\title{
Asymmetric synthesis of cyclopropanes and dihydrofurans based on phosphine oxide chemistry $\dagger$
}

\author{
David J. Fox, * Sean Parris, Daniel Sejer Pedersen, Charles R. Tyzack and Stuart Warren
}

\author{
Received 15th May 2006, Accepted 21st June 2006 \\ First published as an Advance Article on the web 6th July 2006 \\ DOI: 10.1039/b606874j
}

The asymmetric synthesis of $\gamma$-azido trans-cyclopropyl ketones is accomplished via a short, simple and efficient sequence. The cyclopropanation step is achieved by an intramolecular nucleophilic ring closure, with a diphenylphosphinate leaving group, to give trans-cyclopropane exclusively. $\beta$-Keto-diphenylphosphine oxides cyclise to form optically active dihydrofurans. All possible diastereoisomers of dihydrofurans can be prepared selectively starting from the same olefin.

Although the cyclopropane ring is a highly strained structure, it is found in a wide variety of naturally occurring compounds including terpenes, pheromones, fatty acid metabolites and unusual amino acids. ${ }^{1,2}$ The rigidity of the three-membered ring makes it an appealing structural unit for the preparation of molecules with defined orientation of pendant functional groups. The stereocontrolled synthesis of cyclopropanes has therefore been the centre of much research effort. ${ }^{3}$ The area of homogeneous metalcatalysed asymmetric addition of carbenes to olefins has been explored vigorously since the first examples were reported by Noyori and co-workers. ${ }^{4,5}$ Methods involving palladium, ${ }^{6}$ copper, ${ }^{7-11}$ cobalt, ${ }^{12-14}$ ruthenium, ${ }^{14}$ and rhodium ${ }^{11,15-17}$ have been reported. Asymmetric versions of the Simmons-Smith reaction ${ }^{18-21}$ have also been used extensively in synthesis. ${ }^{22}$ Michael-induced ring closure reactions to produce enantio-enriched cyclopropanes have also been studied using chloro-allyl amides, ${ }^{23,24}$ sulfur ylides, ${ }^{25-27}$ sulfoxonium and sulfonium ylides, ${ }^{28-30}$ sulfoximines, ${ }^{31}$ nitrogen ylides, ${ }^{32,33}$ phosphorus ylides, ${ }^{34,35}$ and phosphonates. ${ }^{36}$ Cascade ring closing reactions involving phosphorus transfer, to generate both nucleophile and leaving group, have yielded cyclopropanes generally with high stereospecificity and selectivity. Phosphine oxides, ${ }^{37-40}$ phosphonates, ${ }^{10,41,42}$ and phosphonium salts ${ }^{43}$ have been employed in this manner. We have previously reported that lithiated $\gamma$-benzoyloxy phosphine oxide 1 (Scheme 1) undergoes a three-step cascade reaction to produce trans-cyclopropane $\mathbf{4}$ in high yield without loss of stereochemical information. ${ }^{38}$

Subjecting independently synthesised intermediates $\mathbf{2}$ and $\mathbf{3}$ to the same reaction conditions also produced cyclopropyl ketone 4. Hence, three different precursors of the same cyclopropyl ketone product are possible. To determine if this approach to cyclopropyl ketones is a general synthetic concept we decided to explore the reaction in more detail. In particular, we were interested in introducing an amino group at the benzylic position to give us protected $\gamma$-amino trans-cyclopropane ketones 8 (Scheme 2). Moreover, we decided to invert the stereochemistry at the benzylic position to see what consequences this would have for the reaction outcome. Rather than a free amine we chose to use an azide

University Chemical Laboratory, Lensfield Road, Cambridge, UK CB2 1EW.E-mail:djf34@cam.ac.uk

$\dagger$ Electronic supplementary information (ESI) available: experimental and analytical details for all compounds. See DOI: 10.1039/b606874j.

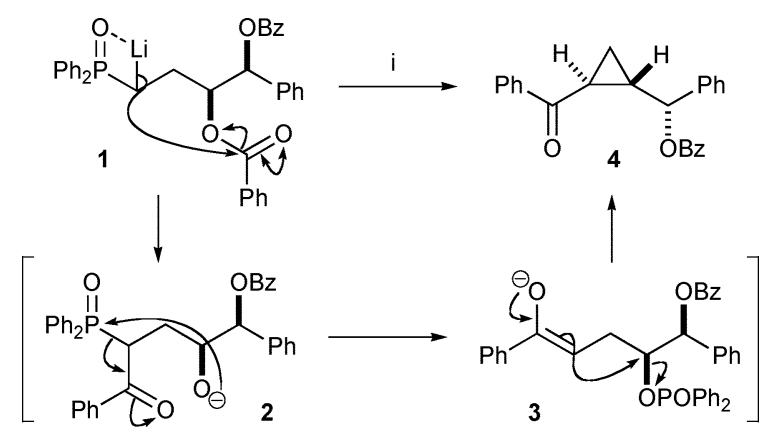

Scheme 1 Reagents and conditions: i) LDA, THF, -78 to $0{ }^{\circ} \mathrm{C}, 95 \%$ ( $>95 \%$ ee).

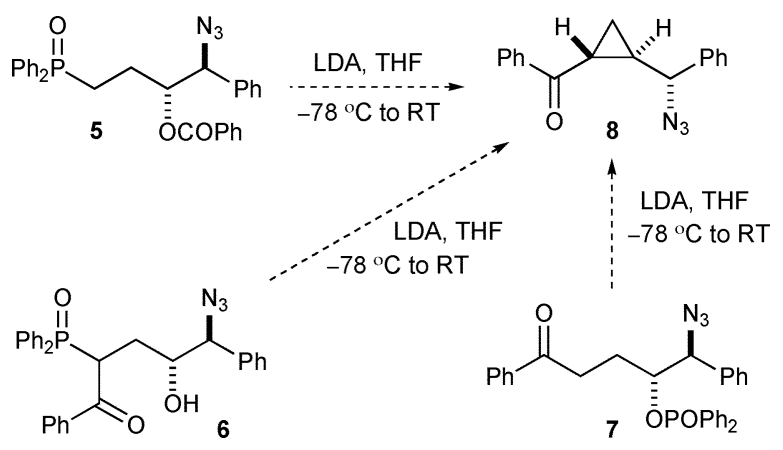

Scheme 2

substituent, which could be transformed into the desired amine equivalent at a later stage by a catalytic hydrogenation or a Staudinger reaction. ${ }^{44}$

We set out to synthesise three cyclopropane precursors 5, 6 and 7 relying on chemistry developed by Chang and Sharpless. ${ }^{45}$ They have demonstrated that styrenes 9 (Scheme 3) can be dihydroxylated and the product diols $\mathbf{1 0}$ converted to cyclic carbonates 11. Regioselective benzylic ring opening with azide then produces anti-azido alcohols $\mathbf{1 2}$.

The synthesis of cyclopropane precursor 5 (Scheme 4) was accomplished from the optically active diol ${ }^{46} 13$, which was converted to cyclic carbonate 14 by treatment with 1,1'-carbonyldiimidazole in dichloromethane. Ring opening of the cyclic carbonate produced the desired regioisomer $\mathbf{1 5}$ exclusively and benzoylation of the alcohol produced cyclopropane precursor $\mathbf{5}$. 


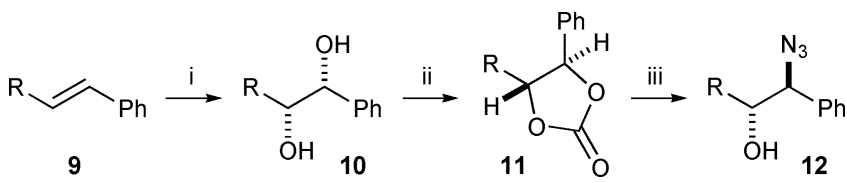

Scheme 3 i) Asymmetric dihydroxylation; reagents and conditions: ii) $(\text { EtO })_{2} \mathrm{CO}, \mathrm{NaOH}$; iii) $\mathrm{NaN}_{3}, \mathrm{H}_{2} \mathrm{O}, \mathrm{DMF}$.

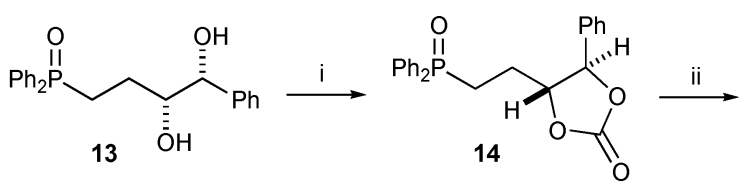<smiles>CC#CP(=O)(CCC(O[C@H](O)C(N)[C@H](O)CCP=O)C(N)c1ccccc1)c1ccccc1</smiles>

Scheme 4 Reagents and conditions: i) 1,1'-carbonyldiimidazole, $\mathrm{CH}_{2} \mathrm{Cl}_{2}$, $97 \%$; ii) $\mathrm{NaN}_{3}, \mathrm{H}_{2} \mathrm{O}, \mathrm{DMF}, 110{ }^{\circ} \mathrm{C}, 87 \%$; iii) PhCOCl, DMAP, $\mathrm{Et}_{3} \mathrm{~N}$, $\mathrm{CH}_{2} \mathrm{Cl}_{2}, 73 \%$.

The synthesis of cyclopropane precursor 6 was attempted by the same method starting from phosphine oxide ${ }^{47} 16$ (Scheme 5). Sharpless asymmetric dihydroxylation of olefin $\mathbf{1 6}$ produced a mixture of the open-chain diol $(4 R, 5 R)-17$ and the cyclic hemiketal $\left(5 S, 1^{\prime} R\right)-\mathbf{1 8}$, which was treated with $1,1^{\prime}$-carbonyldiimidazole in dichloromethane to give cyclic carbonate 19. However, when ring opening was attempted none of the desired azide 6 was obtained. Instead, dihydrofuran $\mathbf{2 0}$ was formed as the only product in high yield. We suspected that the dihydrofuran was formed via intramolecular ring opening of the cyclic carbonate by the carbonyl oxygen with inversion of configuration at C4. An Xray crystal structure of dihydrofuran $\mathbf{2 0}$ confirmed that this was indeed the case $^{48}$ (Scheme 5). Interestingly, when bis-benzoylation of diol ${ }^{38}(4 S, 5 S)-17$ was attempted dihydrofuran 23 was isolated. However, in this instance the dihydrofuran was formed with retention of configuration at $\mathrm{C} 4$ by dehydration of cyclic ketal $\left(5 S, 1^{\prime} S\right)-18$, which was confirmed by comparison of NMR data of dihydrofurans $\mathbf{2 1}$ and $\mathbf{2 3}$.

Ring opening of cyclic carbonates according to the procedure by Chang and Sharpless ${ }^{45}$ requires forcing conditions $\left(110{ }^{\circ} \mathrm{C}\right.$ for $48 \mathrm{~h}$ ) and we hoped that we could suppress dihydrofuran formation by using milder conditions. Hence, the cyclic carbonate was replaced with a more reactive cyclic sulfite. Treatment of diol (4R,5R)-17 (Scheme 6) with thionyl chloride in dichloromethane produced the cyclic sulfite $\mathbf{2 4}$. Treatment of the cyclic sulfite with

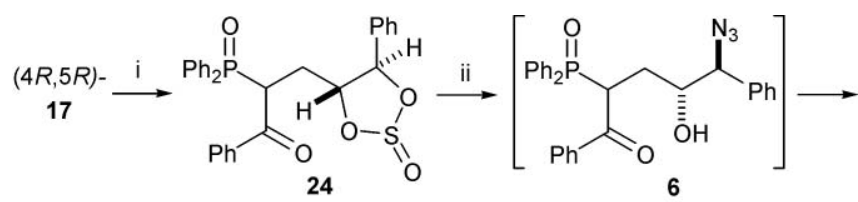

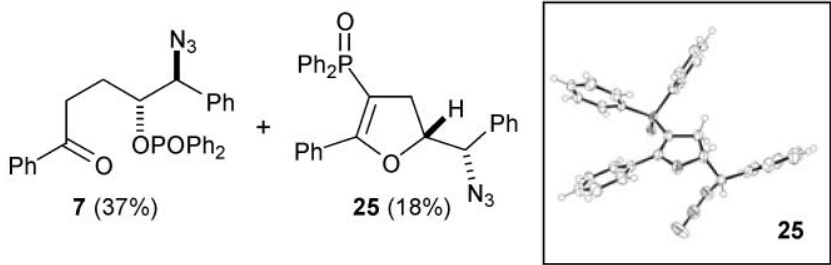

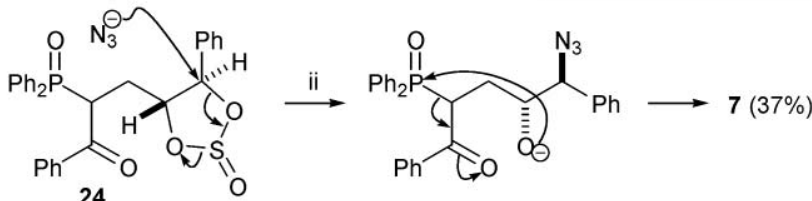
24 $\downarrow$ ii<smiles>CC(c1ccccc1)C(N)[C@H](O)CC(C(=O)O)C(=O)c1ccccc1</smiles>

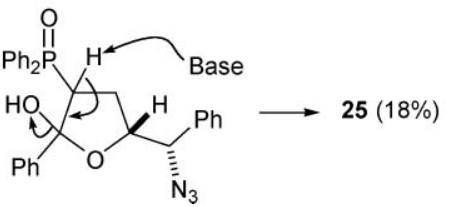

Scheme 6 Reagents and conditions: i) $\mathrm{SOCl}_{2}$, pyridine, $\mathrm{CH}_{2} \mathrm{Cl}_{2}, 47 \%$; ii) $\mathrm{NaN}_{3}, \mathrm{DMF}, 60^{\circ} \mathrm{C}$. Inset: X-ray crystal structure of azide 25 with ellipsoids at $50 \%$ probability.

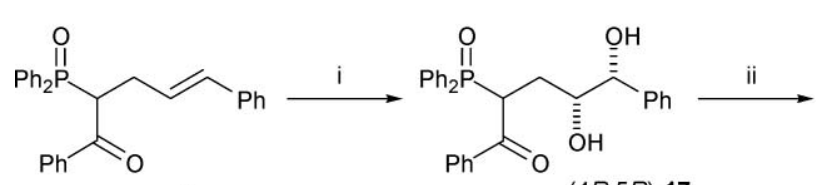<smiles>CC=C(C)C</smiles><smiles>NC(c1ccccc1)[C@H](O)CC(C(=O)c1ccccc1)[PH](=O)c1ccccc1</smiles>

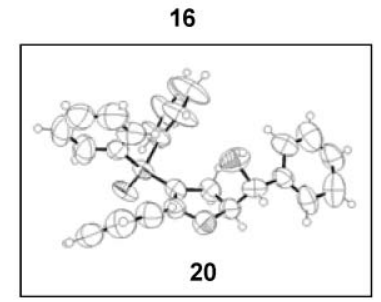<smiles>O=P[R6](=O)c1ccccc1</smiles>

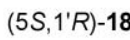<smiles>O=PC1=C(c2ccccc2)O[C@H](C(O)c2ccccc2)C1</smiles><smiles>N#CC#N</smiles><smiles>O=C(c1ccccc1)C(CC(O)([Ge])[C@H](O)c1ccccc1)P=[PH]c1ccccc1</smiles>

(4S,5S)-17<smiles>CC(C)C(C)C(=O)O</smiles><smiles>C1CCCCC1</smiles>

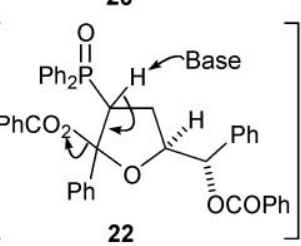

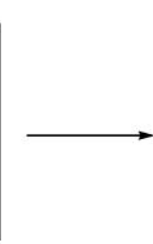

Scheme 5 Reagents and conditions: i) AD-mix- $\beta, 74 \%$; ii) 1,1'-carbonyldiimidazole, $\mathrm{CH}_{2} \mathrm{Cl}_{2}, 98 \%$ (>95\% ee); iii) $\mathrm{NaN}_{3}, \mathrm{H}_{2} \mathrm{O}, \mathrm{DMF}, 110{ }^{\circ} \mathrm{C}, 89 \%$; iv) $\mathrm{PhCOCl}$, pyridine, 95\%; v) $\mathrm{PhCOCl}$, DMAP, $\mathrm{Et}_{3} \mathrm{~N}, \mathrm{CH}_{2} \mathrm{Cl}_{2}, 67 \%$. Inset: X-ray crystal structure of alcohol 20 with ellipsoids at $50 \%$ probability. 
sodium azide in DMF at $60{ }^{\circ} \mathrm{C}$ did indeed produce the desired anti-azido alcohol $\mathbf{6}$. However, under the reaction conditions the reaction did not stop but proceeded to give a mixture of ketone $\mathbf{7}$ and azido dihydrofuran $\mathbf{2 5}$ as well as a small amount $(6 \%)$ of the previously observed dihydrofuran $\mathbf{2 0}$. Ketone 7 and dihydrofuran 25 can be formed after ring opening of the cyclic sulfite by either phosphinoyl transfer or dehydration of the cyclic ketal (Scheme 6). An X-ray crystal structure of dihydrofuran $\mathbf{2 5}$ confirmed the proposed stereochemistry. ${ }^{48}$ Ketone 7 is one of the desired cyclopropane precursors and was spectroscopically identical to the same compound synthesised by a different method (vide infra).

In the light of these experiments we concluded that it was unlikely that cyclopropane precursor $\mathbf{6}$ would provide an easy entry to cyclopropyl ketones and the approach was abandoned in favour of the remaining two cyclopropane precursors 5 and 7. However, the discovery that dihydrofurans such as $\mathbf{2 0}$ and $\mathbf{2 3}$ (Scheme 5) can be obtained as single diastereoisomers is of some interest and will be discussed in more detail below.

Olefin $^{47} 26$ was the starting point for the synthesis of the remaining cyclopropane precursor 7 (Scheme 7). Asymmetric dihydroxylation of olefin $\mathbf{2 6}$ gave diol $\mathbf{2 7}$ in excellent enantiomeric excess. Conversion of diol 27 to cyclic carbonate $\mathbf{2 8}$ using 1,1'carbonyldiimidazole in dichloromethane followed by regioselective ring opening of the cyclic carbonate with sodium azide gave exclusively the desired regioisomer 29. Phosphinoylation of alcohol 29 with diphenylphosphinoyl chloride in pyridine produced cyclopropane precursor 7 .

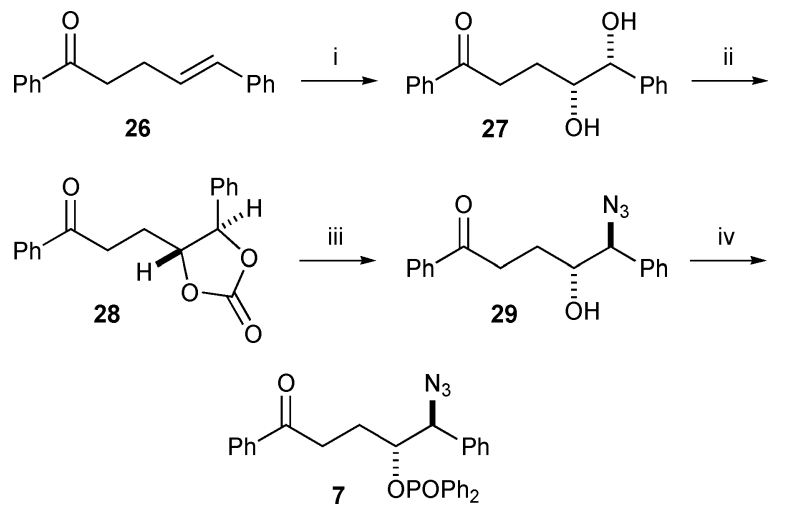

Scheme 7 Reagents and conditions: i) AD-mix- $\beta, 94 \%$ (>95\% ee); ii) $1,1^{\prime}$-carbonyldiimidazole, $\mathrm{CH}_{2} \mathrm{Cl}_{2}, 92 \%$; iii) $\mathrm{NaN}_{3}, \mathrm{DMF}, \mathrm{H}_{2} \mathrm{O}, 110{ }^{\circ} \mathrm{C}$, $92 \%$; iv) $\mathrm{Ph}_{2} \mathrm{POCl}$, pyridine, $83 \%$.

Cyclopropane precursors 5 and $\mathbf{7}$ were treated with LDA in $\mathrm{THF}$ at $-78^{\circ} \mathrm{C}$ and slowly allowed to warm to room temperature (Scheme 8). Phosphine oxide 5 underwent the three-step cascade reaction to give the desired cyclopropane 8 and ketone 7 produced the desired cyclopropane $\mathbf{8}$ by anionic ring closure to give the target cyclopropane. No cis-cyclopropane product was observed, presumably because the two substituents on the forming ring prefer to be anti in the transition state. In both cases the enantiomeric excess of cyclopropane 8 was determined to be $>92 \%$ by NMR of Mosher's amide derivatives. The free amine necessary for this purpose was obtained by converting azide $\mathbf{8}$ to the amine by a Staudinger reaction $\left(\mathrm{PPh}_{3}, \mathrm{THF}, \mathrm{H}_{2} \mathrm{O}\right){ }^{44}$

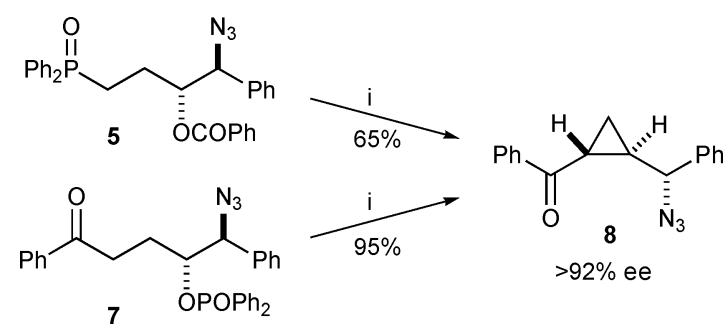

Scheme 8 Reagents and conditions: i) LDA, THF, $-78{ }^{\circ} \mathrm{C}$ to room temperature.

From the results above it is evident that cyclopropane precursor 7 is ideally suited for our purpose. The synthetic sequence is short with an excellent overall yield (five steps, $62 \%,>92 \%$ ee) from easily prepared starting materials. Moreover, all experimental procedures are simple and inexpensive and the products are easily purified using conventional techniques. The method was applied to the synthesis of cyclopropane $\mathbf{3 5}$ starting from olefin ${ }^{49} \mathbf{3 0}$ (Scheme 9). Asymmetric dihydroxylation of olefin $\mathbf{3 0}$ gave diol 31 in excellent enantiomeric excess. Owing to the sensitive furan we anticipated that the Sharpless procedure for ring opening cyclic carbonates with sodium azide might prove too harsh. Hence, we decided to convert diol $\mathbf{3 1}$ to a cyclic sulfite, which could be ring opened using milder conditions. Reaction of diol $\mathbf{3 1}$ with thionyl chloride and pyridine in dichloromethane gave cyclic sulfite $\mathbf{3 2}$. Ring opening of the cyclic sulfite using sodium azide in DMF at $60{ }^{\circ} \mathrm{C}$ produced the desired anti-azido alcohol $\mathbf{3 3}$ as a single regioisomer. Treatment of alcohol $\mathbf{3 3}$ with diphenylphosphinoyl chloride, triethylamine and DMAP in dichloromethane produced cyclopropane precursor 34. Cyclopropanation of phosphinate 34 using LDA in THF gave the target cyclopropane 35 albeit in a low yield. However, no optimisation was undertaken and we expect that the final cyclopropanation step could be improved. The enantiomeric excess of cyclopropane $\mathbf{3 5}$ was determined to be $>96 \%$ by NMR analysis of Mosher's amide derivatives made from the free amine obtained by a Staudinger reaction. ${ }^{44}$

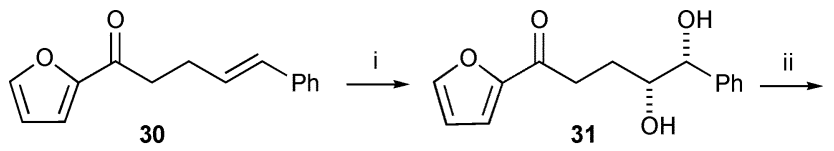

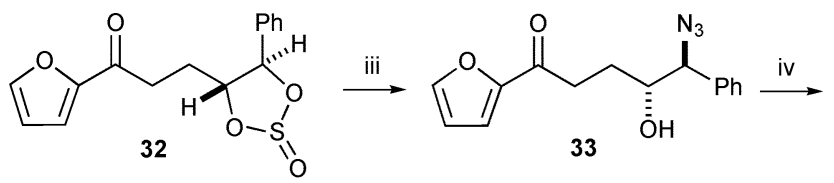<smiles>N[C@H](C(=O)C1C[C@H]1C(=O)c1ccco1)[C@@H](N)c1ccccc1</smiles>

Scheme 9 Reagents and conditions: i) AD-mix- $\beta, 65 \%$ (>93\% ee); ii) $\mathrm{SOCl}_{2}$, pyridine, $\mathrm{CH}_{2} \mathrm{Cl}_{2}, 99 \%$; iii) $\mathrm{NaN}_{3}$, DMF, $60^{\circ} \mathrm{C}, 84 \%$; iv) $\mathrm{Ph}_{2} \mathrm{POCl}$, $\mathrm{Et}_{3} \mathrm{~N}, \mathrm{DMAP}, \mathrm{CH}_{2} \mathrm{Cl}_{2}, 88 \%$; v) LDA, THF, $-78^{\circ} \mathrm{C}$ to room temperature, $30 \%$ (>96\% ee).

As described above (Scheme 5) the treatment of cyclic carbonate 19 with sodium azide resulted in the formation of dihydrofuran $\mathbf{2 0}$ with inversion of stereochemistry at the $\mathrm{C} 4$ position. Moreover, we found that it was possible to prepare the diastereomeric 
Table 1 Synthesis of dihydrofuran 20 from cyclic carbonate 19 (Scheme 5)

\begin{tabular}{llllllll}
\hline Entry & Base & Solvent & Time & Temp $/{ }^{\circ} \mathrm{C}$ & Conversion $(\%)$ & Isolated yield (\%) \\
\hline 1 & $\mathrm{NaN}_{3}$ & $\mathrm{DMF}$ & $48 \mathrm{~h}$ & 110 & $100^{a}$ & 89 \\
2 & $\mathrm{NaH}$ & $\mathrm{DMF}$ & $19 \mathrm{~h}$ & 110 & $100^{a}$ & 80 & - \\
$3^{b}$ & - & $\mathrm{DMF}^{7}$ & $15 \mathrm{~d}$ & 70 & $62^{c}$ & - \\
$4^{b}$ & - & $\mathrm{CD}_{3} \mathrm{CN}$ & $48 \mathrm{~h}$ & 70 & $0^{c}$ & - \\
$5^{b}$ & $\mathrm{Et}_{3} \mathrm{~N}$ & $\mathrm{CD}_{3} \mathrm{CN}$ & $19 \mathrm{~d}$ & 70 & $66^{c}$ & $100^{c}$ & 85
\end{tabular}

${ }^{a}$ Monitored by TLC. ${ }^{b}$ Experiments performed in NMR tubes containing $5 \mathrm{mg}$ of 19 in $0.5 \mathrm{~cm}^{3}$ solvent, heated oil bath. ${ }^{c}$ Monitored by ${ }^{1} \mathrm{H}$ NMR.

dihydrofuran $\mathbf{2 3}$ with retention of configuration at $\mathrm{C} 4$ starting from diol $(4 S, 5 S)-17$. Because the stereochemistry of the diol is controlled in the asymmetric dihydroxylation this potentially gives a method for the selective synthesis of all four possible dihydrofuran diastereoisomers starting from the same olefin. In addition, the synthetic route makes it possible to vary the C4- and $\mathrm{Cl}^{\prime}$-substituents considerably. Hence, a wide range of dihydrofurans should be readily accessible by this approach. The cyclisation of cyclic carbonate 19 to give dihydrofuran 20 was studied using a range of conditions (Table 1).

As it can be seen from Table 1 the cyclisation will occur even in neat DMF (entry 3). However, dimethylamine, a common impurity in $\mathrm{DMF}$, may be acting as a base to accelerate the cyclisation. For comparison the same reaction conditions were examined with acetonitrile as the reaction medium (entry 4), which resulted in no detectable dihydrofuran formation by NMR. NaH (entry 2), triethylamine (entry 5) and DBU (entries 6 and 7) produced the desired dihydrofuran $\mathbf{2 0}$ in moderate to high yields. However conditions using DBU in dichloromethane (entry 7) proved to be superior due to ease of handling, short reaction time and simple purification to give dihydrofuran $\mathbf{2 0}$ in high yield. Optimised conditions for the synthesis of dihydrofuran diastereoisomer 36 and 20 starting from diol (4R,5R)-17 (Scheme 10) were identified. Treatment of the diol with a small amount of thionyl chloride in methanol resulted in the rapid formation of dihydrofuran 36. Alternatively, conversion to the cyclic carbonate followed by addition of DBU in situ gives dihydrofuran 20.

The stereochemistry of dihydrofuran 36 was confirmed by conversion to the previously described azide 25 (Scheme 6) by mesylation of the $\mathrm{Cl}^{\prime}$-alcohol and displacement of the mesylate with sodium azide. This proved to be a simple method for derivatisation at the $\mathrm{Cl}^{\prime}$-position, which was demonstrated by the synthesis of sulfides $\mathbf{3 7}$ and $\mathbf{3 8}$ via displacement of the mesylates with benzene thiolate. The possibility of reducing the dihydrofurans to give tetrahydrofurans was also investigated. We anticipated that good facial selectivity could be achieved due to the substituent at the C2-position. Catalytic hydrogenation of dihydrofuran 20 with Pearlman's catalyst in a mixture of methanol and acetic acid at atmospheric pressure as expected gave exclusive reduction from the face opposite the $\mathrm{C} 2$-substituent. The stereochemistry of tetrahydrofuran 39 was confirmed by X-ray crystallography ${ }^{48}$ (Scheme 10).

Similar methods for the synthesis of dihydrofurans have been reported for the cyclisation of the oxygens of stabilised enolates unto iodonium ions, ${ }^{50-55}$ seleniranium ions, ${ }^{56-58}$ Michael acceptors. ${ }^{59-61}$ and epoxides. ${ }^{62}$ However, unlike the previously reported strategies the present method has the advantage that it is ideally suited for

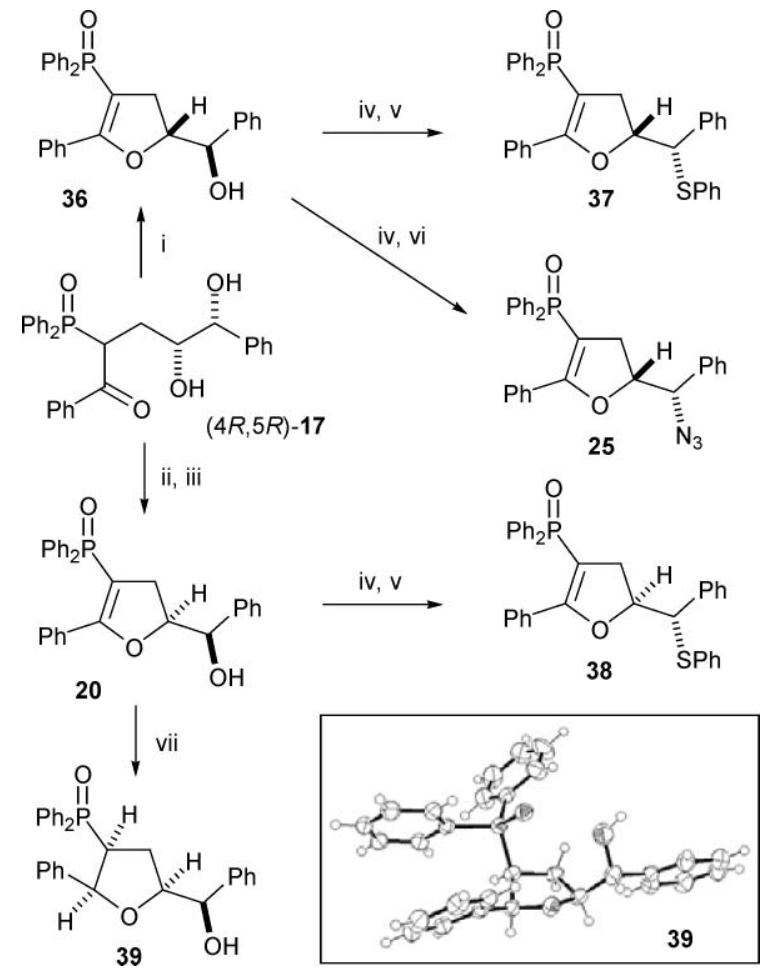

Scheme 10 Reagents and conditions: i) $\mathrm{SOCl}_{2}, \mathrm{MeOH}, 63 \%$; ii) $1,1^{\prime}$-carbonyldiimidazole, $\mathrm{CH}_{2} \mathrm{Cl}_{2}$; iii) DBU, 63\% (2 steps); iv) $\mathrm{MsCl}, \mathrm{Et}_{3} \mathrm{~N}$, $\mathrm{CH}_{2} \mathrm{Cl}_{2}$; v) PhSH, NaH, THF, 37: 45\% (2 steps), 38: 40\% (2 steps); vi) $\mathrm{NaN}_{3}$, DMF, $60{ }^{\circ} \mathrm{C}, 62 \%$ (2 steps); vii) $\mathrm{Pd}(\mathrm{OH})_{2} / \mathrm{C}, \mathrm{H}_{2}, \mathrm{MeOH}, \mathrm{AcOH}$, $58 \%$. Inset: X-ray crystal structure of THF 39 with ellipsoids at $50 \%$ probability.

making optically active dihydrofurans. We are currently seeking to extend this methodology to the synthesis of other substituted heterocycles.

\section{Acknowledgements}

We thank Dr John Davies for crystallography and the EPSRC for financial assistance towards the purchase of the Nonius CCD diffractometer. D. S. P. thanks the Alfred Benzon Foundation, Cambridge Philosophical Society and Nordea Danmark Fonden for financial support.

\section{References and notes}

1 W. A. Donaldson, Tetrahedron, 2001, 57, 8589.

2 C. H. Stammer, Tetrahedron, 1990, 46, 2231. 
3 H. Lebel, J.-F. Marcoux, C. Molinaro and A. B. Charette, Chem. Rev., 2003, 103, 977.

4 H. Nozaki, H. Takaya, S. Moriuti and R. Noyori, Tetrahedron, 1968, 24, 3655 .

5 H. Nozaki, S. Moriuti, H. Takaya and R. Noyori, Tetrahedron Lett., 1966, 43, 5239.

6 S. Vangveravong and D. E. Nichols, J. Org. Chem., 1995, 60, 3409.

7 R. E. Lowenthal, A. Abiko and S. Masamune, Tetrahedron Lett., 1990, 31, 6005.

8 D. A. Evans, K. A. Woerpel, M. M. Hinman and M. M. Faul, J. Am. Chem. Soc., 1991, 113, 726.

9 R. E. Lowenthal and S. Masamune, Tetrahedron Lett., 1991, 32, 7373.

10 D. A. Evans, K. A. Woerpel and M. J. Scott, Angew. Chem., Int. Ed. Engl., 1992, 31, 430.

11 M. P. Doyle, Asymmetric Addition and Insertion Reactions of Catalytically-Generated Metal Carbenes, Wiley-VCH, New York, 2nd edn., 2000, ch. 5, pp. 191-228.

12 T. Fukuda and T. Katsuki, Synlett, 1995, 825.

13 T. Fukuda and T. Katsuki, Tetrahedron, 1997, 53, 7201.

14 T. Niimi, T. Uchida, R. Irie and T. Katsuki, Tetrahedron Lett., 2000, 41, 3647.

15 M. P. Doyle, Q. L. Zhou, A. B. Dyatkin and D. A. Ruppar, Tetrahedron Lett., 1995, 36, 7579 .

16 T. Nagashima and H. M. L. Davies, J. Am. Chem. Soc., 2001, 123, 2695.

17 C. A. Merlic and A. L. Zechman, Synthesis, 2003, 8, 1137.

18 H. Takahashi, M. Yoshioka, M. Ohno and S. Kobayashi, Tetrahedron Lett., 1992, 33, 2575.

19 H. Kitajima, Y. Aoki, K. Ito and T. Katsuki, Chem. Lett., 1995, 1113.

20 H. Kitajima, K. Ito, Y. Aoki and T. Katsuki, Bull. Chem. Soc. Jpn., 1997, 70, 207.

21 A. B. Charette and H. Juteau, Tetrahedron, 1997, 53, 16277.

22 A. G. M. Barrett and K. Kasdorf, Chem. Commun., 1996, 325.

23 S. Hanessian, A. Gomtsayan, A. Payne, Y. Hervé and S. Beaudoin, J. Org. Chem., 1993, 58, 5032.

24 S. Hanessian, D. Andreotti and A. Gomtsayan, J. Am. Chem. Soc., $1995,117,10393$.

25 E. J. Corey and M. Chaykovsky, J. Am. Chem. Soc., 1962, 84, 867.

26 E. J. Corey and M. Chaykovsky, J. Am. Chem. Soc., 1965, 87, 1353.

27 E. J. Corey and M. Jauntelat, J. Am. Chem. Soc., 1967, 89, 3912.

28 D. Ma and Z. Ma, Tetrahedron Lett., 1997, 38, 7599-7602.

29 D. Ma, Y. Cao, Y. Yang and D. Cheng, Org. Lett., 1999, 1, 285.

30 D. Ma and Y. Jiang, Tetrahedron: Asymmetry, 2000, 11, 3727.

31 S. G. Pyne, Z. Dong, B. W. Skelton and A. H. White, J. Org. Chem., 1997, 62, 2337.

32 C. D. Papageorgiou, M. A. Cubillo de Dios, S. V. Ley and M. J. Gaunt, Angew. Chem., Int. Ed., 2004, 43, 4641.

33 C. D. Papageorgiou, S. V. Ley and M. J. Gaunt, Angew. Chem., Int. Ed., 2003, 42, 828

34 F. N. Palmer and D. K. Taylor, J. Chem. Soc., Perkin Trans. 1, 2000, 1323.

35 T. D. Avery, N. F. Jenkins, M. C. Kimber, D. W. Lupton and D. K. Taylor, Chem. Commun., 2002, 28.

36 M. C. Kimber and D. K. Taylor, J. Org. Chem., 2002, 67, 3142.

37 P. M. Ayrey and S. Warren, Tetrahedron Lett., 1989, 30, 4581.

38 T. Boesen, D. J. Fox, W. Galloway, D. S. Pedersen, C. R. Tyzack and S. Warren, Org. Biomol. Chem., 2005, 3, 630.
39 L. Horner, H. Hoffmann and V. G. Toscano, Chem. Ber., 1962, 95, 536. 40 P. Wallace and S. Warren, J. Chem. Soc., Perkin Trans. 1, 1988, 2971. 41 R. A. Izydore and R. G. Ghirarde, J. Org. Chem., 1973, 38, 1790.

42 W. S. Wadsworth, Jr. and W. D. Emmons, J. Am. Chem. Soc., 1961, 83, 1733.

43 E. E. Schweitzer and W. S. Creasy, J. Org. Chem., 1971, 36, 2379.

44 H. Staudinger and J. Meyer, Helv. Chim. Acta, 1919, 2, 635.

45 H.-T. Chang and K. B. Sharpless, Tetrahedron Lett., 1996, 37, 3219.

46 A. Nelson and S. Warren, J. Chem. Soc., Perkin Trans. 1, 1997, 2645.

47 D. J. Fox, D. S. Pedersen and S. Warren, Chem. Commun., 2004, 2598.

48 Crystal data for 20. $\mathrm{C}_{29} \mathrm{H}_{25} \mathrm{O}_{3} \mathrm{P}, M=452.46$, hexagonal, space group $P 6_{1}, a=11.1634(1), b=11.1634(1), c=33.8352(5) \AA, a=90, \beta=$ $90, \gamma=120^{\circ}, U=3651.68(7) \AA^{3}, Z=6, \mu($ Mo-K $\alpha)=0.141 \mathrm{~mm}^{-1}$, 16946 reflections collected at 200(2) K using an Oxford Cryosystems Cryostream cooling apparatus, $3114\left(R_{\mathrm{int}}=0.046\right) ; R_{1}=0.058, w R_{2}=$ $0.142[I>2 \sigma(I)]$, absolute structure parameter $-0.02(17)$.

Crystal data for $25 . \mathrm{C}_{29} \mathrm{H}_{24} \mathrm{~N}_{3} \mathrm{O}_{2} \mathrm{P}, M=477.48$, triclinic, space group $P 1, a=8.4713(3), b=8.5479(3), c=17.4621(6) \AA, a=83.267(2), \beta=$ $83.693(2), \gamma=74.518(2)^{\circ}, U=1206.09(7) \AA^{3}, Z=2, \mu(\mathrm{Mo}-\mathrm{K} \alpha)=$ $0.146 \mathrm{~mm}^{-1}, 12870$ reflections collected at $180(2) \mathrm{K}$ using an Oxford Cryosystems Cryostream cooling apparatus, $8246\left(R_{\text {int }}=0.068\right) ; R_{1}=$ $0.070, w R_{2}=0.165[I>2 \sigma(I)]$, absolute structure parameter 0.01(13).

Crystal data for 39. $\mathrm{C}_{29} \mathrm{H}_{27} \mathrm{O}_{3} \mathrm{P}, M=454.48$, orthorhombic, space group $P 2_{1} 2_{1} 2_{1}, a=5.9419(1), b=14.3610(3), c=26.6529(7) \AA, U=$ 2274.34(9) $\AA^{3}, Z=4, \mu(\mathrm{Mo}-\mathrm{K} \alpha)=0.151 \mathrm{~mm}^{-1}, 14297$ reflections collected at 180(2) K using an Oxford Cryosystems Cryostream cooling apparatus, $2966\left(R_{\mathrm{int}}=0.095\right) ; R_{1}=0.046, w R_{2}=0.103[I>2 \sigma(I)]$, absolute structure parameter $-0.02(13)$.

CCDC reference numbers 297304-297306. For crystallographic data in CIF or other electronic format see DOI: $10.1039 / \mathrm{b} 606874 \mathrm{j}$.

49 D. J. Fox, D. S. Pedersen and S. Warren, Org. Biomol. Chem., 2006, DOI: $10.1039 / \mathrm{b} 606873 \mathrm{a}$.

50 R. Antonioletti, F. Bonadies and A. Scettri, Tetrahedron Lett., 1988, 29, 4987.

51 J. Iqbal and A. Pandey, Synth. Commun., 1990, $20,665$.

52 C. W. Lee and D. Y. Oh, Heterocycles, 1996, 43, 1171.

53 A. Lattanzi, F. Sagulo and A. Scettri, Tetrahedron: Asymmetry, 1999, 10, 2023.

54 R. Antonioletti, S. Malancona and P. Bovicelli, Tetrahedron, 2002, 58, 8825

55 H. A. Stefani, D. O. Silva, I. M. Costa and N. Petragnani, J. Heterocycl. Chem., 2003, 40, 163.

56 W. P. Jackson, S. V. Ley and J. A. Morton, J. Chem. Soc., Chem. Commun., 1980, 1028.

57 W. P. Jackson, S. V. Ley and A. J. Whittle, J. Chem. Soc., Chem. Commun., 1980, 1173.

58 H. A. Stefani, N. Petragnani, C. A. Brandt, D. G. Rando and C. J. Valduga, Synth. Commun., 1999, 29, 3517.

59 M. Miyashita, T. Kumazawa and A. Yoshikoshi, J. Org. Chem., 1980, 45, 2945.

60 S. T. Kabanyane and D. I. Magee, Can. J. Chem., 1992, 70, 2758.

61 J. L. Garrido, I. Alonso and J. C. Carretero, J. Org. Chem., 1998, 63, 9406.

62 R. Antonioletti, G. Righi, L. Oliveri and P. Bovicelli, Tetrahedron Lett., 2000, 41, 10127. 